\title{
NATIONAL PEDIATRIC BLOOD CLUB
}

Use of Intravenous Immune Gamma Globulin in Pregnancy: A Possible Means of Preventing Neonatal Thrombocytopenia

\author{
Wednesday, April 29, 1987 \\ 7:00 P.M. - $9: 30$ P.M. \\ NORTH BALLROOM \\ (Hotel Convention Center)
}

Co-Chairman: Dr. William Krivit and Dr. James B. Busse1

\section{Agenda}

\author{
$7: 00$ \\ Introduction: Dr. William Krivit, Univ. of Minnesota \\ $7: 10-7: 40$ \\ Immune Thrombocytopenia in Pregnancy and Newborn \\ Dr. James B. Busse1, Corne11 \\ $7: 40-8: 10$ \\ Physiology of Gamma Globulin and the Placenta \\ Dr. Clark Smith, Univ. of Minnesota \\ $8: 10-8: 30$ \\ Safety of IVGG Preparations \\ Dr. Margaret Hilgartner, Cornell \\ $8: 30-9: 00$ \\ Platelet Antibody: Levels and Meaning \\ Dr. Janice Gail McFarlane, Milwaukee Blood Center \\ $9: 00-9: 15$ \\ Organizational Plans for Study \\ Dr. William Krivit, Univ. of Minnesota \\ $9: 15-9: 30$ \\ Summarization \\ Dr. Irving Schulman, Stanford
}

Sponsored by SANDOZ LABORATORIES 